\title{
Hernioplastia diafragmática em cão com pericárdio bovino conservado em solução supersaturada de açúcar
}

[Diaphragmatic hernioplasty in dogs with bovine pericardium preserved in supersaturated sugar solution]

\author{
A. Mazzanti ${ }^{1}$, A.G. Raiser ${ }^{1}$, N.L.Pippi ${ }^{1}$, A.S. Alves ${ }^{2}$, R.X. Faria ${ }^{2}$, \\ M.M. Alievi ${ }^{2}$, F.A. Braga', F.Z. Salbego ${ }^{2}$ \\ ${ }^{1}$ Universidade Federal de Santa Maria \\ Laboratório de Cirurgia Experimental - LACE \\ Faixa de Camobi, km 9 - Campus Universitário \\ 97105-900 - Santa Maria, RS \\ ${ }^{2}$ Estudante de Pós-graduação da UFSM
}

Recebido para publicação em 11 de junho de 2002

Recebido para publicação, após modificações, em 26 de março de 2003

E-mail: mazzal@lince.hcv.ufsm.br

\section{RESUMO}

Foram utilizados sete cães adultos, três machos e quatro fêmeas, sem raça definida, com pesos entre 10 e $22 \mathrm{~kg}$, para avaliação do processo cicatricial do músculo diafragma, na presença do implante de pericárdio bovino conservado em solução supersaturada de açúcar a 300\%. Foi criado um defeito na porção muscular do hemidiafragma esquerdo de dimensões $8,0 \times 5,0 \mathrm{~cm}$. Após a toracotomia no oitavo espaço intercostal esquerdo, o implante heterógeno foi fixado com fio poliamida $n^{\circ} 3-0$ por meio de sutura simples contínua. Decorrido o período pré-estabelecido de pós-operatório, os animais foram submetidos a exames radiográficos simples e contrastado e a estudos macroscópico e histológico. Na avaliação radiográfica, foi verificada presença das silhuetas diafragmática e cardíaca, sem evidências de vísceras abdominais no interior do tórax. Macroscopicamente, notou-se a formação de tecido conjuntivo fibroso semi-transparente que ocluia o defeito diafragmático. O segmento de pericárdio bovino conservado em solução supersaturada de açúcar a 300\%, em temperatura ambiente, é substituído por uma fina camada de tecido conjuntivo fibroso e promove a restauração do defeito no músculo diafragma de cão.

Palavras-chave: cão, diafragma, pericárdio, açúcar, cirurgia

\begin{abstract}
Seven adult mongrel dogs, three males and four females, weighting between 10 and $22 \mathrm{~kg}$ were used to evaluate the diaphragmatic muscle healing process. A defect of $8.0 \times 5.5 \mathrm{~cm}$ was created at the muscular portion of the left hemidiaphragm, through a thoracotomy at the eighth left intercostal space. A segment of bovine pericardium, preserved in 300\% sugar solution, was implanted in the diaphragmatic defect. The heterologous implant was sutured with 3.0 polyamide using simple continuous suture. After the observation period, radiologic analysis and macroscopic and histopathologic evaluations were performed. Upon radiographic examination, there was no evidence of interruption of diaphragmatic outline or increased radiopacity at the implantation site. Histologically, fine connective tissue occluded the diaphragmatic defect. Bovine pericardium preserved in $300 \%$ supersaturated sugar solution at room temperature is replaced by a fine layer of connective fibrous tissue and promote repair of large diaphragmatic defects in dogs.
\end{abstract}

Keywords: dog, diaphragm, pericardium, sugar, surgery 


\section{INTRODUÇÃO}

A hérnia diafragmática é uma patologia encontrada com freqüência na rotina hospitalar de pequenos animais. Pode ser de origem congênita, quando há desenvolvimento incompleto e defeituoso (Touloukian, 1978), e adquirida, nos casos de traumatismos direto ou indireto sobre o diafragma (Wilson, Hayes, 1986).

Na correção de ferida diafragmática, quando há ausência ou perda tecidual (Johnson, 1998) ou em casos de evolução crônica, recomenda-se a utilização de implantes biológicos ou sintéticos, pois a aproximação por primeira intenção pode ocasionar tensão na linha de sutura e conseqüente deiscência da ferida (Eurides et al., 1994). O tecido biológico, sempre que possível, deve ser o escolhido por apresentar certas vantagens quando comparado a outros materiais, principalmente a de permitir que o implante seja incorporado ao organismo receptor (Daleck et al., 1988) ou servir de suporte temporário para o processo cicatricial caracterizado basicamente pela formação de tecido conjuntivo fibroso (Hutson, Azmy, 1985).

Com a finalidade de reconstituir o diafragma de cão, Gallo et al. (1982) testaram pericárdio de bovino e suíno conservado em solução de glutaraldeído e verificaram boa vedação do defeito, sendo histologicamente observada presença de uma camada de tecido conjuntivo sobre o implante. Daleck et al. (1988) implantaram um segmento de peritônio conservado em glicerina e detectaram, após 60 dias, sua substituição por tecido conjuntivo fibroso. Ranzani et al. (1990) estudaram em cão o uso de pericárdio de eqüino conservado em glicerina a 98\%. Após celiotomia mediana pré-umbilical, o hemidiafragma esquerdo foi acessado e reparado com implante, sendo observada, após 60 dias, restauração do diafragma com diminuição progressiva do implante. Matsumoto et al. (1996) empregaram pericárdio homólogo de cão conservado em compostos de polipoxy (Denacol). Os autores notaram na área de implantação boa oclusão do defeito e infiltração por tecido conjuntivo, fibroblastos e células inflamatórias (macrófagos e linfócitos). Mazzanti et al. (2001) avaliaram a cicatrização de um segmento muscular homólogo conservado em solução supersaturada de açúcar a 300\% para correção de grandes defeitos de diafragma em cão. Decorridos 120 dias de pós-operatório, os autores observaram substituição do segmento muscular conservado por uma fina camada de tecido conjuntivo fibroso quase transparente e preservação da silhueta diafragmática.

Várias soluções podem ser utilizadas na conservação de material biológico como a betapropiolactona, o liqüido de Hamks (Latteri et al., 1966), o glutaraldeído (Gallo et al., 1982), a glicerina a 98\% (Pigossi et al., 1971; Daleck et al., 1988; Ranzani et al., 1990) e, mais recentemente, solução supersaturada de açúcar (Mazzanti et al., 2001). O açúcar comum ou sacarose de cana-de-açúcar vem sendo utilizado na rotina médica para tratamento de feridas infectadas (Weiss et al., 1984; Raiser, Badke, 1987). Na forma granulada apresenta efeito cicatrizante (Prata et al., 1988), além do poder antimicrobiano sobre alguns tipos de bactérias freqüentemente isoladas de feridas cirúrgicas (Costa Neto et al., 1997). Acredita-se que a hiper-osmolaridade ocasionada pelo açúcar torne o meio inadequado para o crescimento e sobrevivência bacteriana e, também, pelo seu alto poder higroscópico contribua para a redução do edema (Weiss et al., 1984). Com base nessas propriedades, quando em forma sólida, despertou-se o interesse em estudar o açúcar em forma de solução supersaturada para fins de conservação de membrana biológica.

Na maioria dos estudos sobre a reparação do diafragma com material sintético ou biológico o período máximo de pós-operatório estabelecido variou entre 30 e 60 dias (Daleck et al., 1988; Ranzani et al., 1990; Eurides et al., 1994). Isto pode omitir informações importantes sobre o processo cicatricial que ocorreu após essa fase. Segundo Ranzani et al. (1990), as características definitivas do processo cicatricial ocorrem com 30 dias de pós-operatório, ao contrário do verificado por Mazzanti et al. (2001) que, ao empregarem músculo diafragma conservado em solução supersaturada de açúcar a 300\% na reparação de defeitos no diafragma de cão, obtiveram diferentes resultados entre os animais do grupo de 30 dias, de 75 e de 120 dias. 
O objetivo deste trabalho foi estudar o processo cicatricial do diafragma de cão por um período de 270 dias, na presença do pericárdio bovino conservado em solução supersaturada de açúcar a 300\%, mediante análises macro e microscópica e radiográfica da área de implantação.

\section{MATERIAL E MÉTODOS}

Foram utilizados sete cães adultos sem raça definida, com peso variando de 10 a $22 \mathrm{~kg}$ e que se encontravam clinicamente sadios. Após jejum prévio de 12 horas, os animais foram pré-medicados com sulfato de morfina (Dimorf. Cristália do Brasil, São Paulo, SP) $(1,0 \mathrm{mg} / \mathrm{kg})$ associado a sulfato de atropina (Atropina Santisa Injetável. Santisa Laboratório Farmacêutico. Bauru, SP) $(0,044 \mathrm{mg} / \mathrm{kg})$, ambos por via intramuscular, seguido de tricotomia da região torácica lateral esquerda. A indução anestésica foi feita com tiopental sódico (Thiopentax. Cristália - Produtos Químicos e Farmacêuticos Ltda. Itapira, SP) (12,5mg/kg de peso corporal, IV) e, em seguida, cada animal foi intubado com sonda orotraqueal e mantido em plano de anestesia cirúrgica com isoflurano (Isoflurane. Cristália - Produtos Químicos e Farmacêuticos Ltda. Itapira, SP) a 2,5V\% em oxigênio a 100\%, sob ventilação artificial controlada. Com a contenção dos animais em decúbito lateral direito, realizou-se anti-sepsia do campo operatório com álcool-iodo-álcool.

Para a preparação da solução supersaturada de açúcar (Açúcar Cristal Peneirado. Copersucar. São Paulo, SP) a $300 \%$, foram utilizados 300 gramas de açúcar cristalizado em 100 mililitros de água tri-destilada, obtendo-se, no final, uma solução na proporção 3:1 homogeneizada. Para montagem do banco de implante, o segmento de pericárdio bovino foi obtido no setor de patologia veterinária da Universidade Federal de Santa Maria de animais que morreram mas que não apresentavam alterações macroscópicas nessa estrutura. O segmento foi irrigado copiosamente com solução fisiológica a $0,9 \%$ e colocado em frasco estéril contendo solução supersaturada de açúcar a 300\%, previamente homogeneizada. Decorridas 48 horas, a solução foi trocada e o segmento de pericárdio permaneceu imerso para conservação e armazenamento pelo período de 30 dias, em temperatura ambiente. O implante heterógeno foi removido do frasco com solução de açúcar 15 minutos antes do implante, irrigado abundantemente com solução salina e imerso numa cuba rim estéril contendo solução fisiológica a $0,9 \%$, em temperatura ambiente para hidratação. O retalho de pericárdio bovino foi preparado confeccionando-se um segmento de dimensões suficientes para ocluir o defeito diafragmático provocado.

O acesso ao músculo diafragma foi feito mediante toracotomia no oitavo espaço intercostal esquerdo. Após a identificação do músculo diafragma e com auxílio de uma lâmina radiográfica estéril de dimensões $8,0 \times 5,0 \mathrm{~cm}$, foi demarcada uma área do músculo diafragma esquerdo com quatro pontos de reparo de fio poliamida (Fio de Nylon Grilon. Indústria Nacional de Plásticos, SP) n ${ }^{\circ}$ 3-0 em cada ângulo do defeito. Em seguida foi removido com bisturi, por entre os pontos de reparo, um segmento do músculo diafragma, resultando num defeito de mesmas dimensões. O implante foi fixado às bordas da ferida diafragmática sendo utilizado o mesmo tipo de fio, por meio de sutura contínua simples.

A toracorrafia foi realizada com pontos simples contínuos com fio de poliamida 3-0, sendo o de pele com pontos simples separados com fio mononáilon (Mononylon 3-0. Ethicon. Johnson \& Johnson. São José dos Campos, SP) $n^{\circ}$ 3-0. O restabelecimento da pressão negativa intratorácica foi feito por insuflação pulmonar quando da aplicação do último ponto do primeiro plano de sutura. A insuflação do pulmão foi controlada com auxílio de uma válvula (Narcomatic 2000. Narcosul S.A. Porto Alegre, RS), evitando pressão intratraqueal superior a $20 \mathrm{~cm}$ de $\mathrm{H}_{2} \mathrm{O}$. Na permanência de um eventual pneumotórax residual, o ar foi extraído por toracocentese no sétimo espaço intercostal.

Foram utilizados ampicilina sódica (Ampicilina sódica. Ariston. Ariston Indústria Química. São Paulo, SP) (20mg/kg de peso corporal, IV), 30 minutos antes do procedimento e flunixin meglumine (Banamine. Schering-Plough. Rio de Janeiro, RJ) (1,0mg/kg de peso corporal, IM), repetido no pós-operatório por mais dois dias. A ferida cirúrgica cutânea foi submetida a curativo local com solução salina e os pontos de pele retirados com oito dias de pós-operatório. Decorridos 270 dias de pós-operatório, os animais foram submetidos a exame radiográfico do tórax nas posições lateral e dorso-ventral, sendo repetidos os mesmos posicionamentos 
para estudos contrastados de vísceras do sistema digestório no interior do tórax, empregando-se sulfato de bário (Bariogel. Cristália. Produtos Químicos Farmacêuticos. Itapira, SP) (Ticer, 1987).

Para análise macroscópica da área de implantação e coleta de fragmentos para estudo em microscopia de luz, os animais foram submetidos a eutanásia com injeção intravenosa de tiopental sódico ${ }^{3}(12,5 \mathrm{mg} / \mathrm{kg}$ de peso corporal, IV), seguido de solução de cloreto de potássio. O material foi fixado em formalina a 10\% por período mínimo de dois dias e os cortes para a histologia corados em HE e TM.

\section{RESULTADOS E DISCUSSÃO}

O acesso ao diafragma pelo oitavo espaço intercostal esquerdo permitiu a confecção do defeito e a sua restauração com implante heterógeno. Para Raiser (1994), a toracotomia empregada nesse espaço tem sido uma opção de abordagem, principalmente quando o diagnóstico permite definir qual o lado comprometido. Outros acessos ao músculo diafragma foram propostos, como a via tóraco-abdominal praticada por Punch e Slatter (1985), sétimo espaço intercostal esquerdo utilizado por Gallo et al. (1982) e Latteri et al. (1966), $10^{\circ}$ espaço intercostal por Mazzanti et al. (2001) e laparotomia mediana por Sweet e Waters (1991), Ranzani et al. (1990) e Faria et al. (1999), porém, impossibilitariam o acesso à cúpula diafragmática obtida pelo oitavo espaço intercostal.

Em todos os animais verificaram-se aderências da área de implantação com estruturas abdominais (Fig. 1B), como o fígado (71\%) e o omento maior (28\%), e torácicas, como os pulmões (71\%) e a pleura parietal (57\%), coincidindo com os achados de Matsumoto et al. (1996), que empregaram pericárdio canino, e de Mazzanti et al. (2001), os quais utilizaram músculo diafragma homólogo para reparo de defeito diafragmático de cão. Esses autores verificaram também que o fígado e os pulmões foram as estruturas mais acometidas, graças à proximidade anatômica desses órgãos com a região da ferida diafragmática reparada. As aderências foram desfeitas manualmente, ao contrário do que foi observado por Mazzanti et al. (2001), cujas aderências encontravam-se firmes, com intensa formação de tecido conjuntivo fibroso. Essa diferença de resposta pode ser atribuída ao tipo de implante utilizado, visto que a solução de conservação foi a mesma.

Nas avaliações radiográficas em posições lateral e dorso-ventral verificaram-se as presenças de silhuetas diafragmática e cardíaca (Fig. 2A, 2B). Para Sullivan e Reid (1990), a indefinição do contorno das silhuetas permite definir a presença de hérnia diafragmática em 97\% dos casos. Johnson (1998) e Raiser (1994) comentaram que a radiografia torácica é o exame de maior eficiência para o diagnóstico de hérnia diafragmática. Neste experimento, foi realizado estudo contrastado do sistema digestório pela maior freqüência do estômago e intestinos no interior do tórax, seguido do fígado e baço, segundo as observações de Johnson (1998).

Na avaliação macroscópica da área de implantação, após 270 dias de observação, foi verificada uma membrana fibrosa delgada semi-transparente que preenchia o defeito diafragmático (Fig. 1A, 1B). Ranzani et al. (1990), ao empregarem pericárdio de eqüino conservado em glicerina a 98\% para restauração de diafragma de cão, notaram até o $60^{\circ}$ dia que o implante assumiu tonalidade mais esbranquiçada.

Microscopicamente e aos 270 dias do procedimento cirúrgico verificou-se na interface tecido receptor/local de implante, penetração de fibras colágenas da região restaurada em direção ao músculo diafragma adjacente. Notou-se, também, que a transição entre o diafragma e o tecido conjuntivo fibroso apresentava definições bem evidentes (Fig. 1C). Daleck et al. (1988), aos 60 dias, notaram na área restaurada do diafragma por peritônio bovino presença de fibras colágenas sem orientações definidas, infiltração de células mononucleares e fibroblastos ao redor e entre as fibras da membrana implantada. O implante heterólogo conservado comportou-se como estrutura de sustentação temporária, substituído progressivamente por tecido conjuntivo fibroso. Gallo et al. (1982), que usaram pericárdio de suíno ou bovino na reparação de diafragma de cão, verificaram presença do enxerto na área reparada decorridos 
cinco meses de implantação. Rodgers et al. (1981) observaram tal ocorrência com dura-máter humana decorridos seis meses de implantação e Matsumoto et al. (1996) não mais detectaram a presença de pericárdio homólogo no diafragma de cão após cinco meses. Os resultados obtidos as semelham-se aos observados por Mazzanti et al. (2001), os quais encontraram diferenças histológicas entre tempos prédeterminados de estudo, e diferem dos encontrados por Ranzani et al. (1990), que definiram a duração do processo cicatricial em 30 dias após implantação de uma membrana biológica.
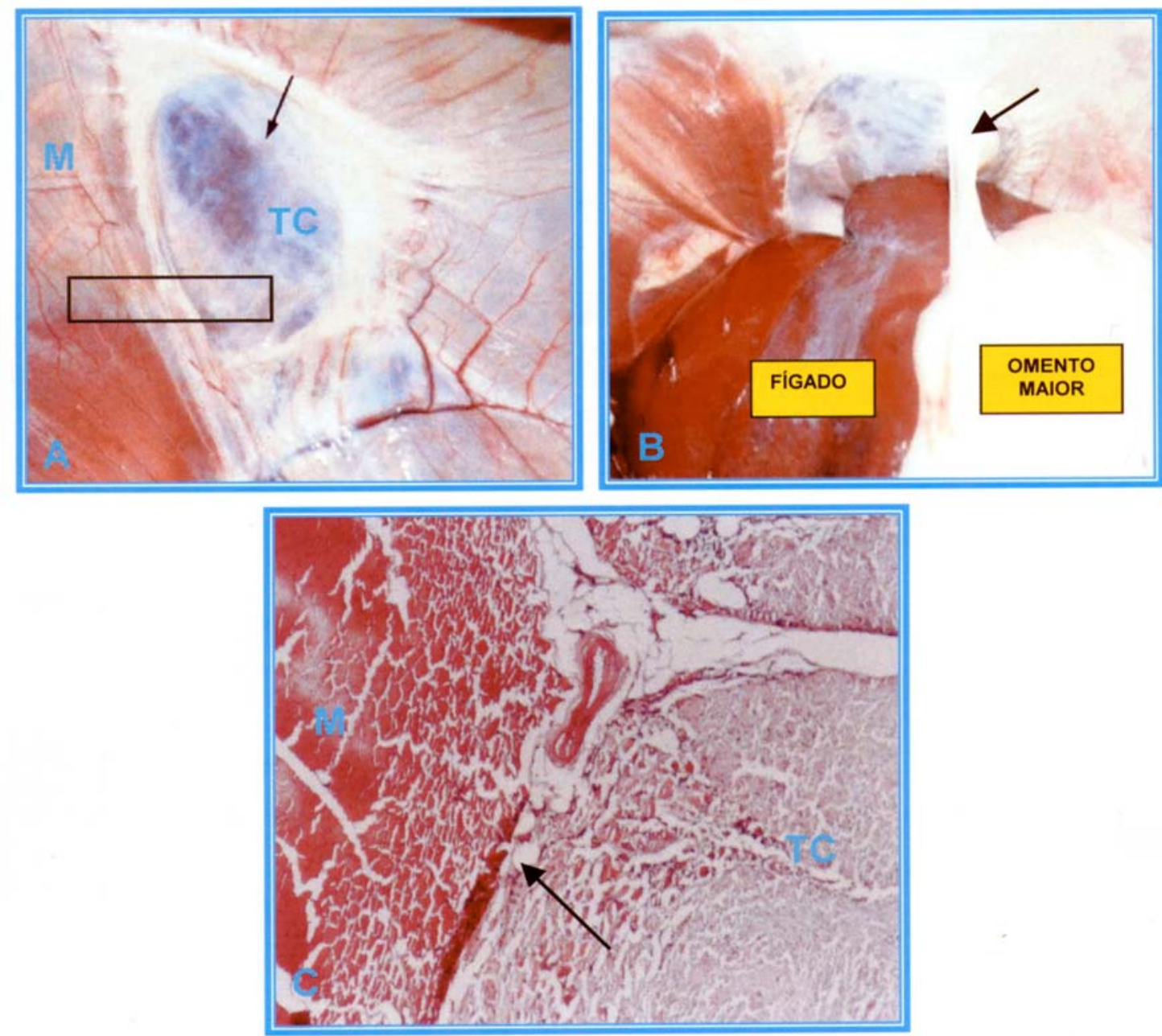

Figura 1. Diafragma (M) de cão submetido a hernioplastia diafragmática com pericárdio bovino conservado em solução supersaturada de açúcar, decorridos 270 dias de pós-operatório. A- Presença de tecido fibroso (TC) delgado preenchendo o defeito diafragmático (seta). B- Aderência do fígado e omento maior com a área reparada (seta) C- Definição (seta) entre o diafragma (M) e o tecido conjuntivo fibroso formado (TC). 

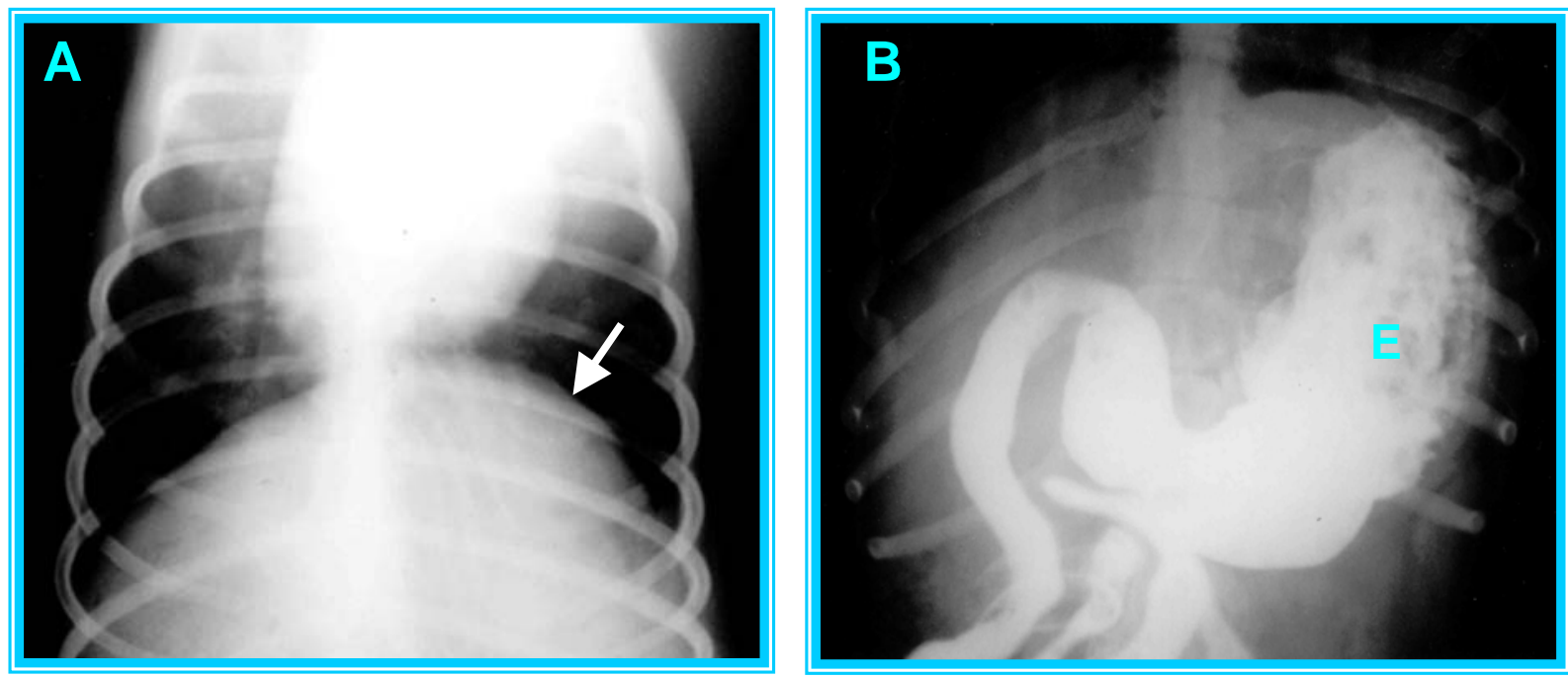

Figura 2. Aspecto radiográfico do tórax e abdome de cão submetido a hernioplastia diafragmática com pericárdio bovino conservado em solução supersaturada de açúcar a 300\%, decorridos 270 dias de pósoperatório. A- presença da silhueta cardíaca e diafragmática (seta). B- verifica-se a após o estudo contrastado, a presença do estômago (E) contido na cavidade abdominal.

As bordas do defeito de $8,0 \times 5,0 \mathrm{~cm}$, provocado no hemidiafragma esquerdo, só foram aproximadas com tensão, justificando a hernioplastia com uso de implantes para reconstrução do diafragma, como recomendado por Deshpande et al. (1983). Na literatura consultada não foi observada padronização quanto ao tamanho do defeito criado no músculo diafragma, sendo encontrada medidas que variaram de 4,0×4,0cm (Ranzani et al., 1990) a 10,0×6,0 cm (Oliveira, 1998). Para Barreiros et al. (1996), que utilizaram o músculo grande dorsal para reparação do diafragma de cão, um defeito de 4,0×5,0cm foi considerado como de grande dimensão. Essa classificação quanto ao tamanho, no entanto, teria maior fundamento se as bordas do defeito criado não pudessem ser reaproximadas ou, se conseguida, permanecessem com grande tensão, a ponto de poder ocasionar deiscência na linha de sutura.

As propriedades medicinais do açúcar como cicatrizantes e bactericidas salientadas por Weiss et al. (1984) e Raiser e Badke (1987) motivaram os autores deste trabalho a formularem uma solução de açúcar com o objetivo de conservação de membranas biológicas. Para isso, um dos fatores considerados foi a definição da concentração bactericida. Segundo as observações de Costa Neto et al. (1997), a solução de açúcar para apresentar efeito antimicrobiano deveria ser acima de $250 \%$, daí a definição de $300 \%$ para este experimento. Apesar de não terem sido realizados estudos microbiológicos da solução conservante de açúcar, não foram detectados sinais de infecção, à semelhança do observado por Latteri et al. (1966), Gallo et al. (1982) e Ranzani et al. (1990), quando empregaram outras soluções conservantes.

A avaliação pós-operatória por nove meses permitiu concluir, de forma segura, que as alterações ocorridas no tecido receptor, após a implantação do segmento de pericárdio heterógeno, são definitivas. $\mathrm{Na}$ maioria das vezes os resultados apresentados em estudos de reparação do diafragma foram obtidos em períodos curtos nos quais o processo cicatricial se caracterizou pela proliferação de tecido conjuntivo fibroso (Daleck et al., 1988; Ranzani et al., 1990; Eurides et al., 1994). Gallo et al. (1982), Matsumoto et al. (1996) e Mazzanti et al. (2001) observaram que a ferida diafragmática cicatrizou mediante a formação de tecido fibroso que se tornava, no decorrer do processo de reparação, de espessura mais fina e aspecto semitransparente, colocando em dúvida a resistência dessa cicatriz. Nesta pesquisa, o tecido cicatricial apresentou as mesmas características citadas e, durante a tração manual, manteve adequada sustentação da região. Apesar de não terem sido feitos testes específicos sobre a resistência da membrana fibrosa 
formada, verificou-se que a área reparada encontrava-se com sustentação adequada durante a tração manual.

\section{CONCLUSÕES}

O uso do pericárdio bovino conservado em solução supersaturada de açúcar a 300\% promove a restauração do defeito no diafragma de cão, mediante a substituição por uma membrana fibrosa, sem apresentar evidências de infecção e de rejeição na área de implantação.

\section{REFERÊNCIAS BIBLIOGRÁFICAS}

BARREIROS, L.J.; RODASKI, S.; SUSKO, I. et al. Uso experimental do músculo grande dorsal autólogo na reparação dos grandes defeitos diafragmáticos no cão. Rev. Setor Ciênc. Agr., v.15, p.141150, 1996.

COSTA NETO, A.A.C.; PAES, J.L.L.; CARVALHO, R.G. et al. Concentração bactericida do açúcar em culturas de Escherichia coli. Rev. Col. Bras. Cir., v.24, p.151-154, 1997.

DALECK, C.R.; DALECK, C.L.M.; ALESSI, A.C. et al. Substituição de um retalho diafragmático de cão por peritônio de bovino conservado em glicerina: estudo experimental. Ars Vet., v.4, p.53-61, 1988.

DESHPANDE, K.S.; KRISHNAMURTHY, D.; NIGAM, J.M. et al. Efficacy of certain biological and synthetic materials used for repair of diaphragmatic defects in bovines. Indian J. Anim. Sci., v.53, p.830834, 1983.

EURIDES, D.; NIGRO, A.J.T.; GOLDENBERG, S. et al. Reparo de defeito provocado no diafragma de cães com segmento livre peritônio-muscular. Estudo experimental. Acta Cirur. Bras., v.9, p.131-135, 1994.

FARIA, R.X. Transposição do músculo reto do abdome para correção de defeito iatrogênico no diafragma em cães. 1999. 32f. Tese (Mestrado em Medicina Veterinária). Universidade Federal de Santa Maria, Santa Maria, RS.

GALLO, J.I.; ARTIÑANO, E.; VAL, F. et al. Glutaraldehyde-preserved heterologous pericardium for the repair of diaphragmatic defects. J. Thoracic Cardiovasc. Surg., v.83, p.905-908, 1982.

HUTSON, J.M.; AZMY, A.F. Preserved dura and pericardium for closure of large abdominal wall and diaphragmatic defects in children. Annals Royal Coll. Surgeons Engl., v.67, p.107-108, 1985.

JOHNSON, K.A. Hérnia diafragmática, pericárdica e hiatal. In: SLATTER, D. Manual de cirurgia de pequenos animais. São Paulo: Manole, 1998. Cap.37, p.559-577.

LATTERI, S.; ROMEO, G.; DI BENEDETTO, A. et al. Ricerche sperimentali sulla riparazioni di diffetti diaframmatici con dura madre. Gion. Ital. Chirur., v.22, p.171-196, 1966.

MATSUMOTO, H.; OGUCHI, Y.; MIYAKE, Y. et al. The use of epoxy patch grafts for repair of experimentally-created diaphragmatic defects in dogs. J. Vet. Med. Sci., v.58, p.685-687, 1996.

MAZZANTI, A.; PIPPI, N.L.; RAISER, A.G. et al. Músculo diafragma homólogo conservado em solução supersaturada de açúcar para reparação de grande defeito no diafragma de cão. Rev. Ciênc. Rural, v.31, p.277-283, 2001.

OLIVEIRA, L.O. Retalho pediculado do músculo grande dorsal para reparo de defeito diafragmático em cães. 1998. 15p. Seminário - Programa de Pós-graduação em Medicina Veterinária. Universidade Federal de Santa Maria, Santa Maria, RS. 
PIGOSSI, N.; RAIA, A.; LEX, A. et al. Estudo experimental sobre o emprego, como implante, da duramáter homógena conservada em glicerina à temperatura ambiente. Rev. Assoc. Med. Bras., v.17, p.263278, 1971.

PRATA, M.B.; HADDAD, C.M.; GOLDENBERG, S. et al. Uso tópico do açúcar em ferida cutânea. Estudo experimental em rato. Acta Cirur. Bras., v.3, p.43-48, 1988.

PUNCH, P.I.; SLATTER, D.H. Diaphragmatic hernias. In: SLATTER, D.H. Textbook of small animal surgery. Philadelphia: Saunders, 1985. Cap.59, p.869-885.

RAISER, A.G. Herniorrafia diafragmática em cães e gatos. Relato de 22 casos e proposição de técnica para corrigir rupturas freno-costais. Braz. J. Vet. Res. Anim. Sci., v.31, p.245-251, 1994.

RAISER, A.G.; BADKE, M.R. Terapia de infecções cirúrgicas com jatos de solução salina e açúcar granulado. Rev. Bras. Med. Vet., v.9, p.125-128, 1987.

RANZANI, J.J.T.; GANDOLFI, W.; FRANCO, M. et al. Implante de pericárdio de eqüino em glicerina em solução de continuidade do diafragma de cão. Braz. J. Vet. Res. Anim. Sci., v.27, p.65-73, 1990.

RODGERS, B.M.; MAHER, J.W.; TALBERT, J.L. The use of preserved human dura for closure of abdominal wall and diaphragmatic defects. Ann. Surg., v.193, p.606-611, 1981.

SULLIVAN, M.; REID, J. Management of 60 cases of diaphragmatic rupture. J. Small Anim. Pract., V.31, p.425-430, 1990.

SWEET, D.C.; WATERS, D.J. Role of surgery in the management of dogs with pathologic conditions of the thorax - part II. Comp. Cont. Educ. Pract. Vet., v.13, p.1671-1677, 1991.

TICER, J.W. Técnicas radiológicas na prática veterinária. 2.ed. São Paulo: Roca, 1987. 523p.

TOULOKIAN, R.J. A “new” diaphragm following prosthetic repair of experimental hemidiaphragmatic defects in pup. Ann. Surg., v.87, p.47-50, 1978.

WEISS, R.G.; NECTOUX FILHO, J.L.; FALLEIRO, R.P.T. et al. Tratamento da ferida operatória infectada: açúcar, uma nova opção. Rev. AMRIGS, v.28, p.337-342, 1984.

WILSON, G.P.; HAYES, H.M. Diaphragmatic hernia in the dog and cat: a 25-year overview. Sem. Vet. Med. Surg. (Small Animals), v.1, p.318-326, 1986. 